\title{
AN ANALYSIS OF EDUCATIONAL GAMES DESIGN FRAMEWORKS FROM SOFTWARE ENGINEERING PERSPECTIVE
}

\author{
${ }^{1}$ Mifrah Ahmad, ${ }^{2}$ Lukman AB. Rahim \& ${ }^{3}$ Noreen Izza Arshad \\ $1,2 \& 3$ Computer and Information Sciences Department, \\ Universiti Teknologi Petronas, Malaysia \\ mifrah09@gmail.com; lukmanrahim@petronas.com.my; \\ noreenizza@petronas.com.my
}

\begin{abstract}
Game-based learning has dominantly embedded itself into a tool of education in the 21 st century. In developing educational games, many researchers have proposed frameworks to define elements of an educational game. This paper presents a survey of the different frameworks for educational games and analyzes these frameworks against several criteria for effective video games, well-designed games and key elements of educational games. The authors will also look at the frameworks support towards learning theories. In addition, the analysis continues in the context of software engineering practices to develop effective educational games.
\end{abstract}

Keywords: Game design frameworks, educational game components, software engineering, game design framework.

\section{INTRODUCTION}

Learning is an ultimate practice of the interpretation and evaluation of knowledge with one's experience which is subsequently translated into skills, values and comprehension (Ge, 2012). There are many ways in which the knowledge can be delivered such as scaffolding, project-based or collaborative learning (Garris, Ahlers, \& Driskell, 2002).

Game-based learning (GBL) is described as the involvement of suitable game mechanics' and recreation of the scenario-based, problem-based, problemoriented learning processes found in games in order to accomplish learning purposes (Kovačević, Minović, Milovanović, De Pablos, \& Starčević, 2013; Lester et al., 2014; Poulsen, 2011). Squire and Jenkins (2003) highlighted that 
a large number of scholars have confidence on computer games to become a learning tool that will inspire the students and enhance their focus on learning in subjects such as chemistry (Romli, Shiratuddin, \& Hashim, 2003), physics (Abang Abu Bakar; 2002), health education (Barker, Quennerstedt, \& Annerstedt, 2013; Mellecker, Witherspoon, \& Watterson, 2013) and mathematics (Ke, 2013), and initiate a pioneering educational paradigm (Tan, Ling, \& Ting, 2007). Furthermore, GBL allows a rich learning context to assist learners to build a higher-level of knowledge through imprecise and confronting opportunities (Van Eck, 2006). In addition, there has been a research which declared that games are capable of tendering 16 learning principles (Gee, 2005).

Researchers' confidence in educational games as a tool to motivate student learning is based on the younger generation's inclination towards playing games (Hussin, Suhaimi, \& Bawi, Dec 2004; Latif, 2007; Omar, Ibrahim, \& Jaafar, 2011; Takaoka, Shimokawa, \& Okamoto, 2011; Tiong \& Yong, 2008). Krotoski (Krotoski, Entertainment, \& Association, 2004) reported that the game industry sector has been rapidly growing over the last decades and other researchers have provided supporting evidence to this fact in the form of increasing gamers population (Lee \& Kim, 2004). Current trends also show the popularity of multi-player online games (MMOG) (Hofer, 2005, McClarty, Orr, Frey, Dolan, Vassila \& Mc Vay Orret al., 2012). Another study by Whitton shows that $63.1 \%$ respondents found games positively motivating in learning, 28.3\% not motivating while 8.6\% demotivating (Whitton, 2007).

Conversely, there have been many conflicts on how to design educational games that is entertaining and at the same time sustaining the learning aspects. For this reason, researchers argue that an educational game should include good game design and suitable learning pedagogy (Amory \& Seagram, 2003; Becker, 2009; Moreno-Ger, Burgos, Martínez-Ortiz, Sierra, \& FernándezManjón, 2008). A recent study has conducted a case study based approach where the authors implemented design-based learning through educational computer game for math subject and how the novice developer's designing thinking and the contents usage for knowledge development can be collaborative in game-making process $(\mathrm{Ke}, 2014)$. The research concluded that there was a great improvement for students to experience activities actively; however, the time was consumed for the development and content deliverance for learners. Hirumi and Stapleton (2009) stated that the research expansion in educational video game production is moving more quickly in design and efficacy, however, not much is known of methodologies that could be used to enhance the game design processes to achieve a better outcome (Hirumi \& Stapleton, 2009). Table 1 summarizes the frequently discussed trends in GBL. 
Table 1

Selected Trends in Education learning (De Freitas \& Oliver, 2006)

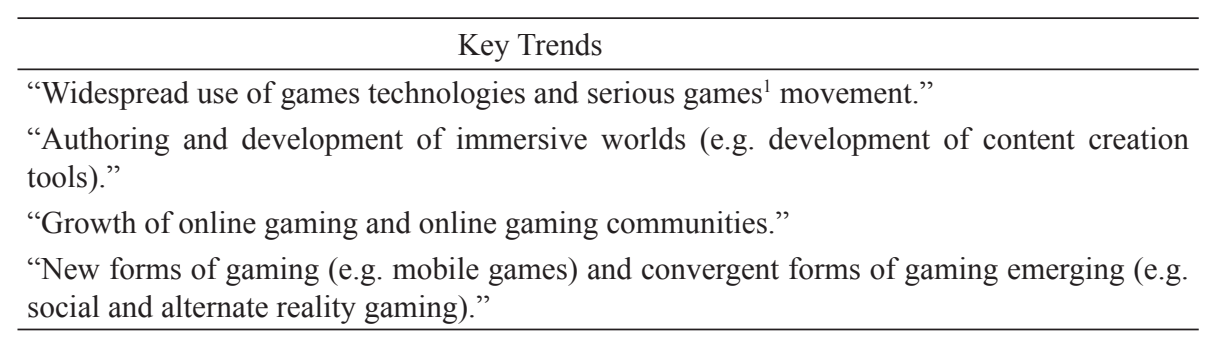

A systematic review of 117 selected literatures was conducted to investigate the educational design frameworks. They were analyzed to investigate and confirm with the criteria of well-designed and effective video games. The key words used to find the literature were game design (2000 - 2014), learning theories (1913 - 2013), frameworks and models (1999 - 2013), subjects or courses of games (2000 - 2014), and other key words such as software engineering in GBL, learning environments, motivational aspects, educational games in case studies, game developing components and key elements of designing educational game (1999 - 2014). In addition to that, literature types were mainly books (9), book section (4), conference proceedings (23), generic (1), journal articles (78), report (1) and thesis (1).

\section{LITERATURE REVIEW}

\section{Learning via Educational Games}

Games are more synonymous to entertainment and fun than learning (Baranowski, Buday, Thompson, \& Baranowski, 2008; Whitton, 2012). Therefore, using games as an effective learning tool is only possible when the games are developed properly and incorporates established education theories.

Educational games are typically developed based on learning theories, pedagogical components, gender preferences and game design components (Baranowski et al., 2008; Gress, Fior, Hadwin, \& Winne, 2010; Hirumi \& Stapleton, 2009; Kruger, 2012; Mikropoulos \& Natsis, 2011). Adapted from Smith (Smith, 1999), the four major learning theories in GBL are behaviorism, cognitivism, humanism and constructivism, which include 16

Serious games are also known as educational games; video games; game-based learning; instructional games 
learning principles. Constructivism theory (Wu, Hsiao, $\mathrm{Wu}, \mathrm{Lin}, \&$ Huang, 2012) deals with human constructing their knowledge subjectively through experience and learning in active process. Behaviorism theory developed by (Thorndike, 1913) deals with learning through a change in behavior or the environment shape behavior and the principle of reinforcement. Cognitivism theory deals with how the memory and prior knowledge plays an important role in learning (Merriam, 1999). Humanism theory deals with factors such as self-determination, the value and potential of the user depending on their dignity (Combs, 1981). A study by Wu, Hsiao, Wu, Lin \& Hang (Wu et al., 2012) shows that only around $14 \%$ of GBL research includes learning theories and the most used is experiential learning and situated learning.

From the learning theories, researchers adopted some of their principles for GBL and some of the adopted theories are:

- Learning is effective when it is lively, goal-oriented, contextualized, attention-grabbing and out of the ordinary (Becker, 2009; Bransford, Brown, \& Cocking, 1999; Bruner, 1961; Gee, 2005; Quinn, 2005).

- $\quad$ Based on the situated learning theory (Arnab, Berta, Earp, De Freits, Popescu, Romeo \& Heart, 2012; Jong, Lee, Lee, \& Shang, 2011; Kebritchi \& Hirumi, 2008), learning in an attentive environment ensures a useful knowledge gain.

- According to the experiential learning theory, instructional environment must be able to assess learner's knowledge, be interactive, provides ongoing feedback and able to sustain attention by adapting levels of challenges that the learner encounters (Dalgarno \& Lee, 2012; Hays, 2005; Herrington \& Oliver, 2000; Kruger, 2012; Smythe, 2012). It is recently proven that instructional game-based learning environment has assisted learner's in improving their learning (Wouters \& Van Oostendorp, 2013).

- A learning environment must be able to be controlled, fundamentally inspiring, and involves active memory with knowledge exchange and/or physical commitment towards learning for the learners to gain knowledge and experience through failure and retry (Klopfer, Osterweil, \& Salen, 2009).

- Learning must be specific to a particular content (Cheng, Lou, Kuo, \& Shih, 2013; Gredler, 1996; Hays, 2005; Ke, 2009; Randel, Morris, Wetzel, \& Whitehill, 1992; Vogel et al., 2006; Wang, Liu, \& Li, 2011; Wolfe, 1997).

- A learning environment should allow four types of actions: 1) Experimentation: the establishment of learning objectives and the activities to be carried out, 2) Reflection: the comparison of results obtained from groups, 3) Activity: the design of the game, which may 
involve other educational materials as reference such as books, internet etc., and 4) Discussion: the reflection on the actual process of learning, and the joint discussion related to the proposed activities.

- $\quad$ Effective learning must balance between challenges and the learners' skills in completing the challenges. This requirement is based on the Flow theory (Admiraal, Huizenga, Akkerman, \& Dam, 2011; Csikszentmihalyi, 1990; Csikszentmihalyi, 1997; Finneran \& Zhang, 2003; Kiili, 2005). The flow theory states the symbiotic relationship between challenges and the skills needed to meet those challenges. The flow experience is assumed to occur when one's skills are neither overmatched nor underutilized to meet a given challenge (Jong, Shang, Lee, \& Lee, 2010; Tham \& Tham, 2012). This balance of challenge and skill is delicate as it can result in the players experiencing apathy (i.e., low challenges, low skills), anxiety (i.e., high challenges, low skills), or boredom (i.e., low challenges, high skills) (Csikszentmihalyi, 1990; Csikszentmihalyi, 1997; Kiili(a), 2005; Kiili(b), 2005).

\section{Effective Educational Game Designs}

Researchers have proposed the requirements/guidelines for effective educational game design. Figure 1 illustrates these requirements.

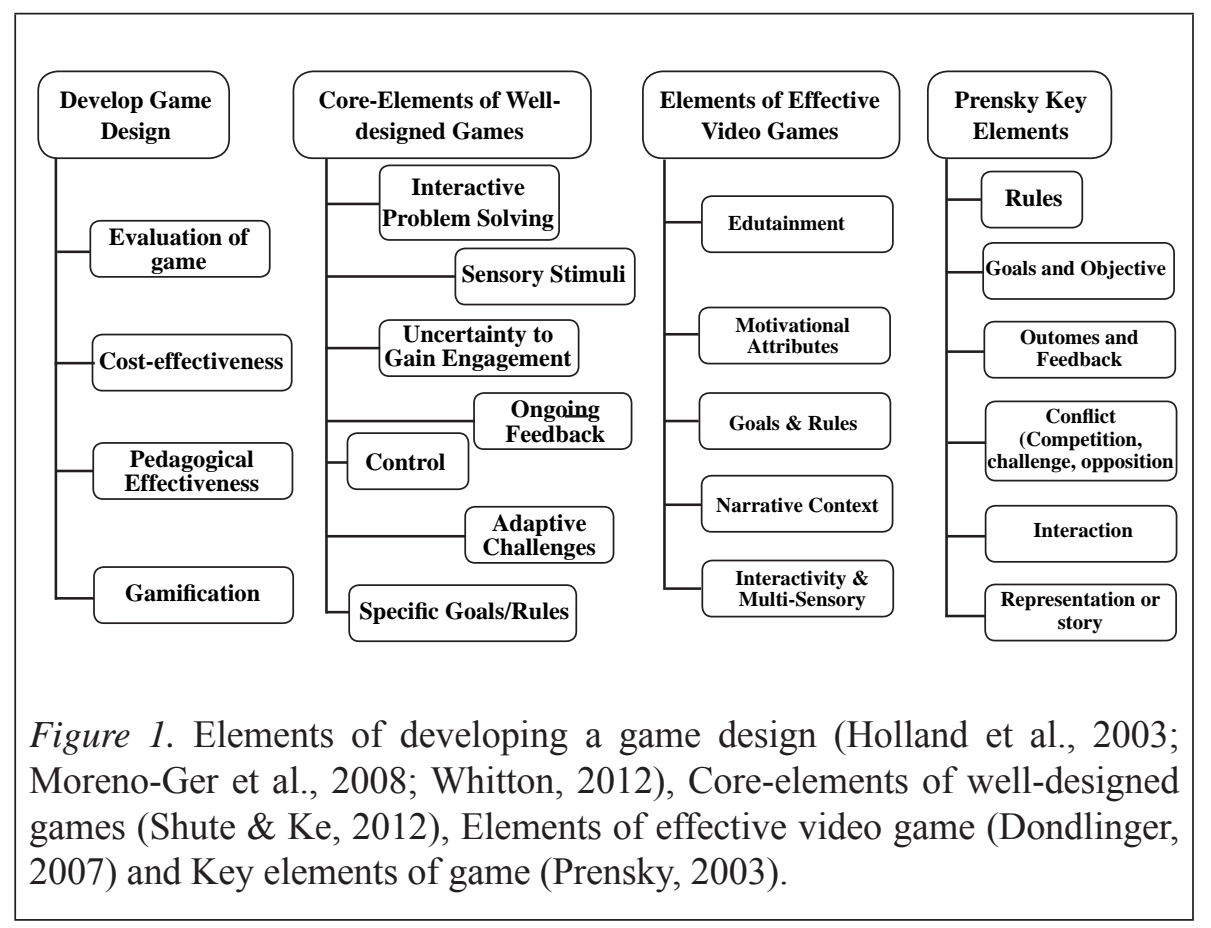


Other than Prensky Key Elements, Van Staalduinen and de Freitas (2010) also listed 12 game elements from the literature and grouped them into four dimensions, which are shown in Figure 2. Some of the game elements appearing in the four dimensions are also mentioned in the core elements of a well-designed game and elements of an effective game (De Freitas \& Jarvis, 2009; De Freitas \& Oliver, 2006).

\begin{tabular}{|l|l|}
\hline \multicolumn{2}{|c|}{ Four-DimensionalFramework } \\
\hline Learner specifics & Pedagogy \\
Profile & Associative \\
Role & Cognitive \\
Competencies & Social/Situative \\
\hline Representation & Context \\
Fidelity & Environment \\
Interactivity & Access to learning \\
Immersion & Supporting resources \\
\hline
\end{tabular}

Figure 2. Game elements grouped in a four dimensional framework

This framework is used to choose an appropriate educational game and learn to earn knowledge correctly (De Freitas \& Jarvis, 2009; De Freitas \& Oliver, 2006). The four dimensions are explained in Table 2.

Table 2

The Four-Dimensional Framework Domains and Their Description

\begin{tabular}{ll}
\hline Domain & Description \\
\hline Context & $\begin{array}{l}\text { Game and its utilization are central to the effectiveness of how the } \\
\text { game consumes it. }\end{array}$ \\
Learner Specific Action & $\begin{array}{l}\text { The learner or learner group is also central to which game is chosen } \\
\text { and utilized. }\end{array}$ \\
Representation & $\begin{array}{l}\text { The game itself has a level of immersion and devotion, familiarity } \\
\text { of interface with the learner group and the internal reality and } \\
\text { narrative of the game for effective learning. } \\
\text { The utilization of games in the learning context, rather than for } \\
\text { Pedagogic Model }\end{array}$ \\
\hline
\end{tabular}

\section{METHODOLOGY}

Developing an educational game is certainly not an effortless job. It engages various viewpoints into consideration, which may consist of the major learning 
theories with their principles, game design components as well as the learning content. A few researches have specified clearly that educational games must merge a good pedagogy structure and a known game design to guarantee education efficiency (Amory \& Seagram, 2003; Fisch, 2005; Garzotto, 2007; Ibrahim \& Jaafar, 2009).

However, developing an educational game is not only about learning theories. If the development is only in the hands of education expert, the outcome will not be fun or attractive, whereas, if game designers take over, the games may be unsuccessful in applying the key pedagogical principles. A study stated that to certify game development, the content experts of the game should work constantly with game designers (Hirumi \& Stapleton, 2009). However, educational game development is not limited to the involvement of game designers and education experts. Other stakeholders can also contribute to the development such as programmers, teachers, instructional designers and students (Ibrahim \& Jaafar, 2009).

A few frameworks have been discussed in literature for educational game development. 12 game elements were analyzed and divided into four dimensions (De Freitas \& Jarvis, 2009; De Freitas \& Oliver, 2006). It is extended further to be used in educational game development and is known as the Four Dimensional Framework (FDF). The extended framework, as being shown in Figure 3, maintains the four dimensions, and extends and adds more elements that should be in an educational game such as instructions, feedback, challenges and interactions.

\begin{tabular}{|l|l|}
\hline Learner Specifics & Pedagogy \\
Challenge & Adaptation \\
Conflict & Assessment/Feedback \\
Progress & Debriefing/Evaluation \\
& Instructions/Help/Hints \\
& Safety \\
\hline Representation\Action-Domain Link & Context \\
Control & Fantasy \\
Interaction (Equipment) & Goal/Objectives \\
Interaction (Interpersonal) & Language/Communication \\
Interaction (Social) & Mystery \\
Location & Pieces or Players \\
Problem-Learner Link & Player Composition \\
Representation & Rules \\
Sensory Stimuli & Theme \\
\hline
\end{tabular}

Figure 3. Four-Dimensional Framework 
FDF is improved further by including the cognitive and instructional approaches into the game process (Staalduinen \& De Freitas, 2010). The framework, as shown in Figure 4, is able to map the design of existing games, serves as a checklist for designers of serious games and provide replicable and scalable immersive game content. The framework also establishes relationships between the elements in the four dimensions. Learning objectives and player goals defines users' engagement in the game and guides their learning. Learner specific game elements are customized to give positive influence towards users learning and behaviours. Appropriate debriefing and system feedback will be given by the game according to the users' achievements to assist the students learning. The students learn from the system feedback and improve (player feedback). The players' feedbacks will influence the learning contents (maintain the current content, move to a more advance topic or go deeper into the same topic) and this will influence learning objectives and player goals.

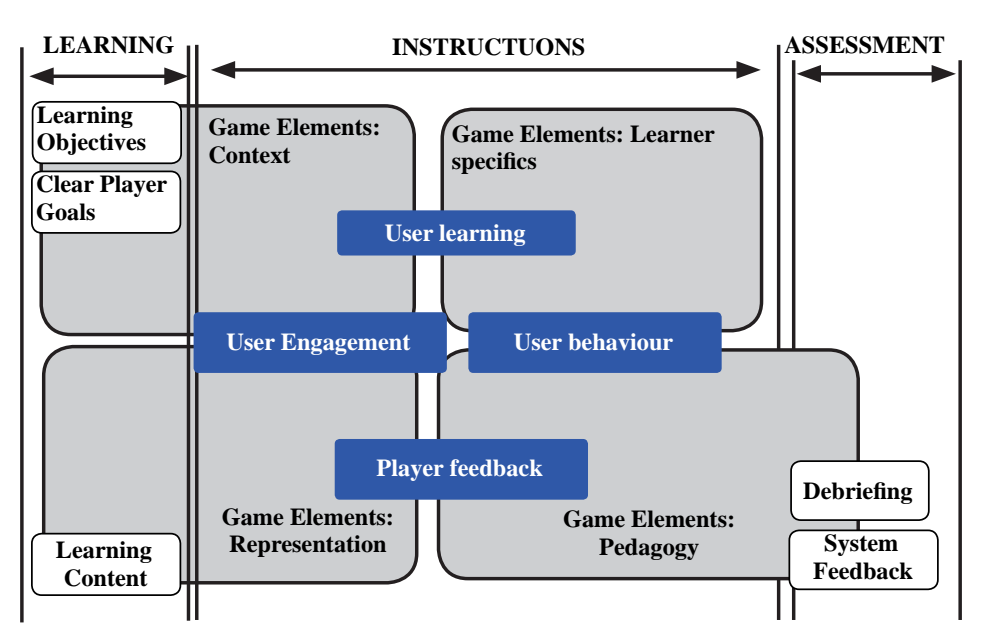

Figure 4. Van Staalduinen and De Freitas (2010) Framework

FDF mainly specifies the elements of educational games and the inclusion of these elements are based on learning theories such as experiential learning. Other researchers have also included the process of learning in their framework. Learner-centered design (LCD) framework has been proposed with the experiential learning at its core. This framework has an adjustable feature to enhance student's learning performance for games that require data input from keyboard (Wang, Chen, \& Tseng, 2010). Three key components of the framework are: 1) learner's personal assortment is created according to their learning progressions, 2) an adjustable/adaptive learning mechanism where playing the game plus providing documentation of experiments that performs a 
comparison between learning techniques for fine-tuning, and 3) a configurable mechanism which provides a cooperative act to adjust content of the game according to changes made. Learner-centered design (LCD) approaches, such as contextual inquiry and participatory design, have been implemented to propose new tools for learners in emerging nation (Lalji \& Good, 2008). Another research proved that adaptive learning in educational games does not depend on student's cognitive or learning styles, thus, they choose educational games based on personal preferences (Hwang, Sung, Hung, \& Huang, 2013). A framework that is based on active learning theory by Garris, Ahlers \& Driskell (Garris et al., 2002) allows education expert to define their own games (Pivec \& Dziabenko, 2004a). Figure 5 shows the model of GBL by Garris et al. (2002).

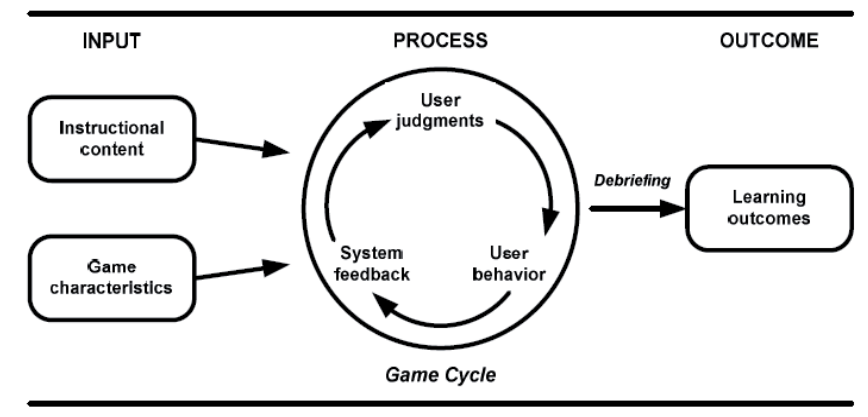

Figure 5. Model of game-based learning by (Garris et al., 2002; Pivec \& Dziabenko, 2004a, 2004b)

Experiential learning does not necessitate teachers as it is exclusively depending upon the useful process accomplished by individual's experience with the game itself. Game play involves interaction with a game through its rules, the connection between the player and the game, challenges and solutions, the plot and the players emotional connection with the plot (Egenfeldt-Nielsen, Smith, \& Tosca, 2008). The experiential gaming model allows game play to link with experiential learning (Kiili, 2005). This shows the process of learning through experiential loop where it is adapted to the outcome of the first problem's solution, then it provides a challenge and continues the loop to experience problems and solve throughout the loop. However, a new aspect is that the flow of learning is an important fact to understand and overcome the challenges to achieve the objective (Kiili, 2005(a); Kiili, 2005(b)). Although the skill level increases and the player can control the game with subject matter, the player endeavors to test different kinds of solutions in order to expand knowledge. Figure 6 shows the experiential framework by Kiili (Kiili, 2005(a); Kiili, 2005(b)). 


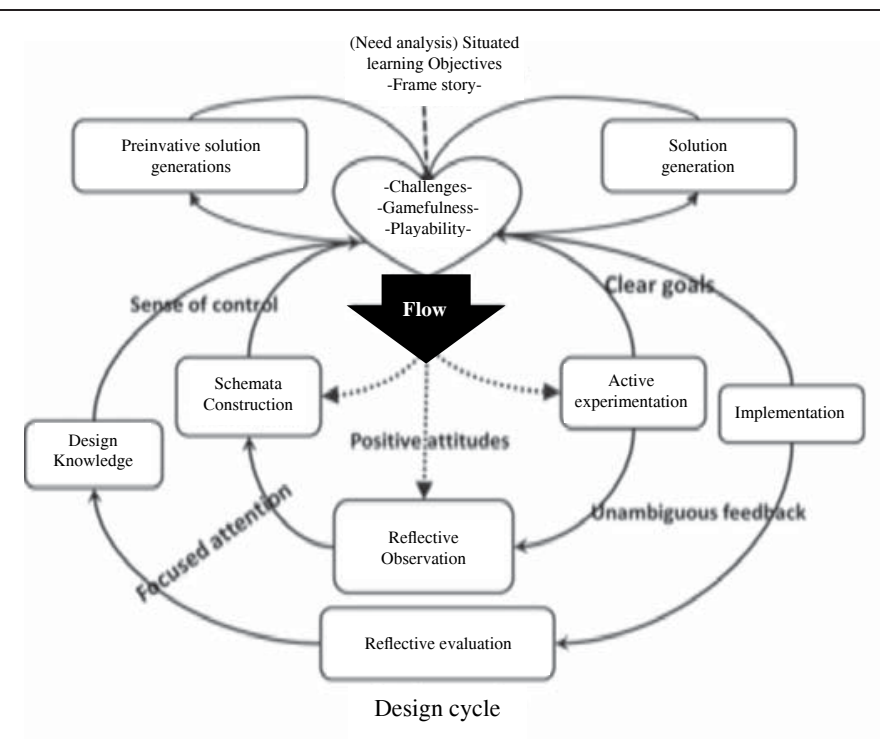

Figure 6. Experiential Gaming Model

Figure 7 shows the flow of computer-aided environment stages (Finneran \& Zhang, 2003) based on the flow theory. The framework consists of flow antecedents, flow experience and flow consequences (Chen, Wigand, \& Nilan, 1999; Hoffman \& Novak, 1996). Flow antecedents consist of educational game elements that are the pre-requisite to effective learning. Flow experience includes the conditions that the users experience when playing the game and flow consequence is the result obtained from the learning experience.

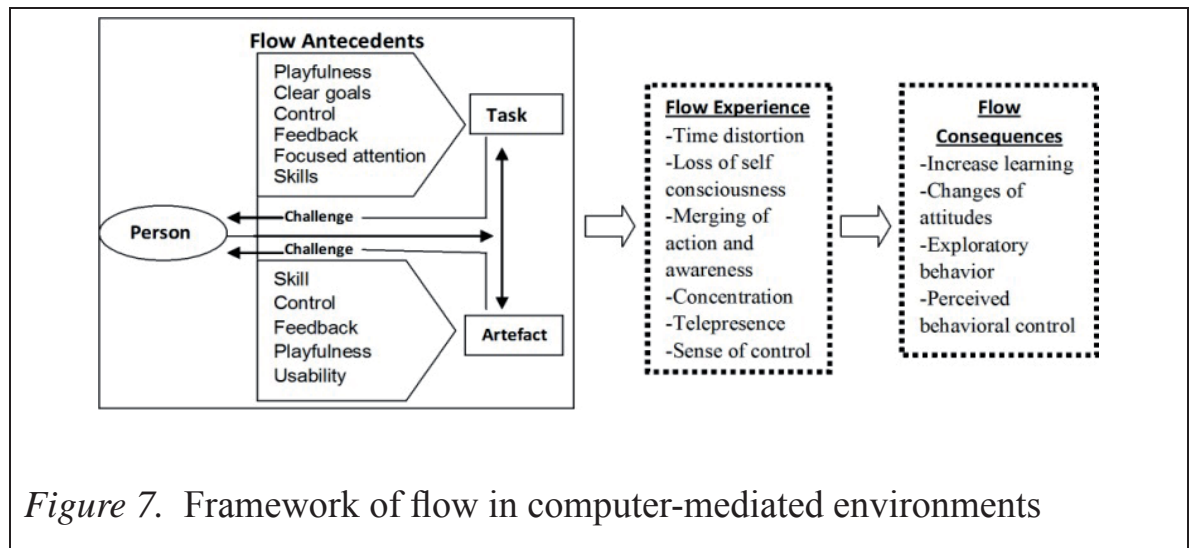

Advancement in the field of educational game framework is the inclusion of elements from the wider education perspective. Education is not only about 
the knowledge and about learning principles. It may include the national education agenda, formal curriculum, management of learning institute, etc.

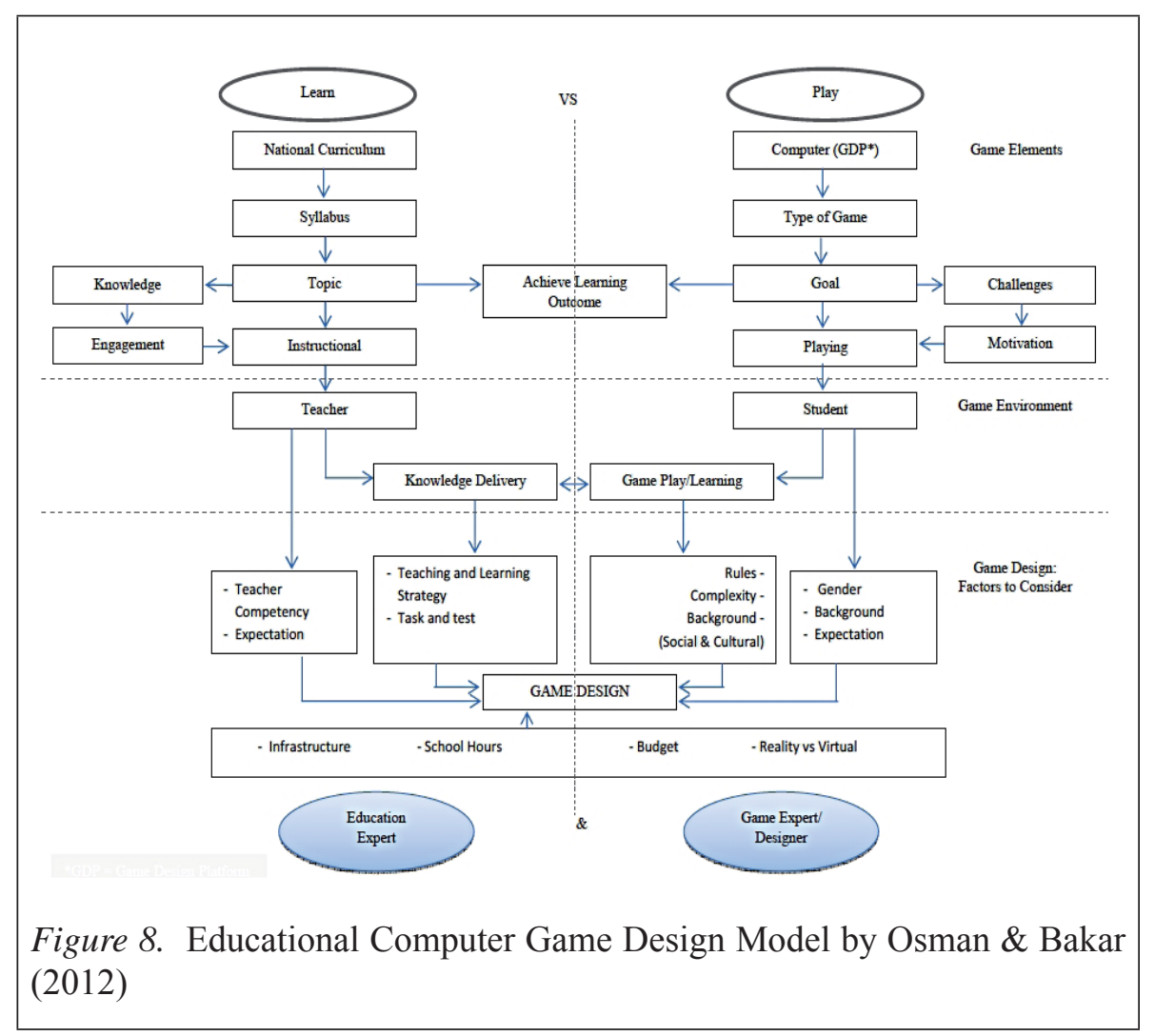

A game based learning model by (Osman \& Bakar, 2012) was proposed for Malaysian chemistry classroom and a few challenges were faced when it was implemented. The authors argued that availability and sustainability of the games in the market and in classroom is fluctuating, adopting learner's requirement and designing a computer game for classroom is hectic and barriers that hinder the implementation of educational computer games is typical and vague. Therefore, the authors introduced a model with five factors: pedagogical factor (teaching strategy), game-play design factor (rules integrated in the game), teacher factor, student factor, and other factors such as availability of technology.

Yue, Zin \& Jaafar (2009) proposed a framework for history education that also includes the country's curriculum, moral values and psychology in addition to the learning theories and educational elements mentioned in FDF. Figure 9 shows the framework by Yue et al. 


\section{HISTORY EDUCATION GAME DESIGN WITH GBL APPROACH}

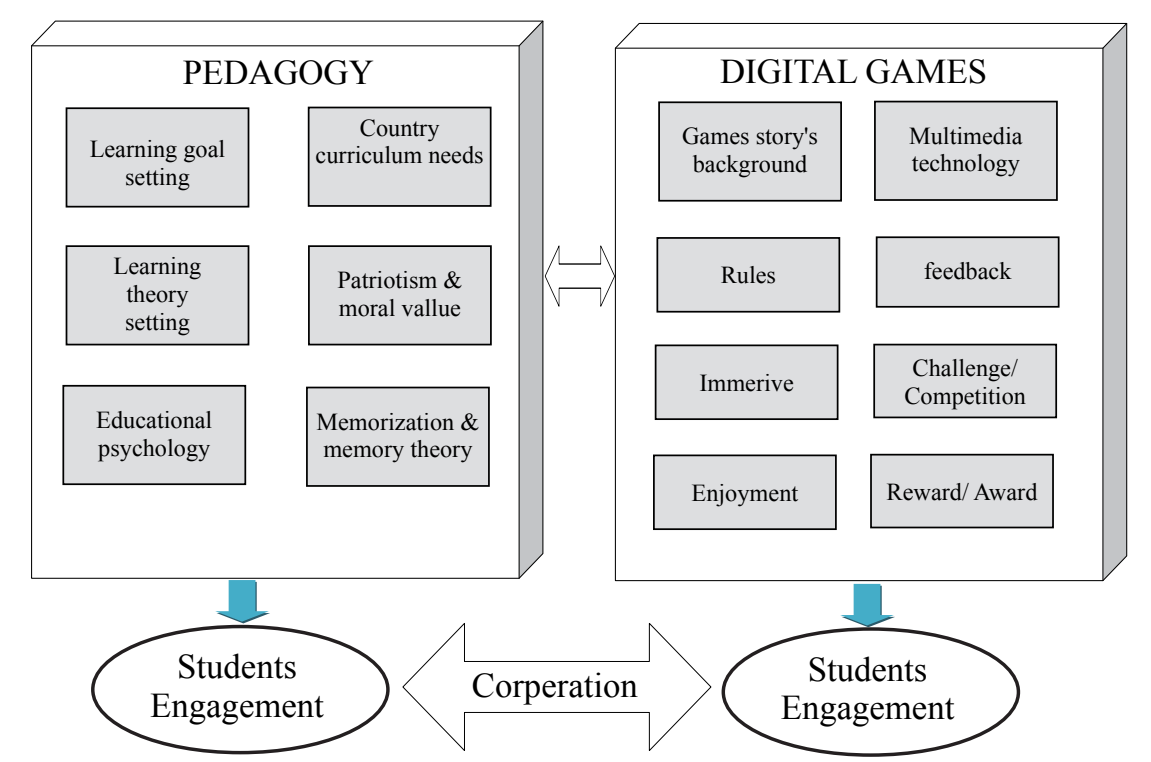

Figure 9. Proposed components in DGBL Model for History Educational Games Design

A more radical advancement in the field of educational game frameworks is the shift from educational perspective to game development perspective. The change of perspective changes the elements that researchers included in the framework from learning elements to gaming elements and software components. Furthermore, the representation of the frameworks starts to look like a game architecture than a learning framework. Research is even performed to find ways of lowering game development cost such as 1) developing simple and cost-effective game with less technical specifications such as (online toolkits), 2) learning from games rather than learning with them, 3) providing learner's agency with creators rather than simple players (Whitton, 2012). Other development related research being performed is development team's dynamics (Charsky \& Ressler, 2011; Dede, Clarke, Ketelhut, Nelson, \& Bowman, 2005; Li et al., 2010), collaborations and communications (Tiong \& Yong, 2008).

Figure 10 is an educational game model that shows a component of an educational game that uses multi-agent technology (Mills \& Dalgarno, 2007). The problems, concepts and hints are similar to the challenges and instructions in FDF. Constraint based model, tutoring agent and level agent are representing rules, feedback and progress elements in FDF. 


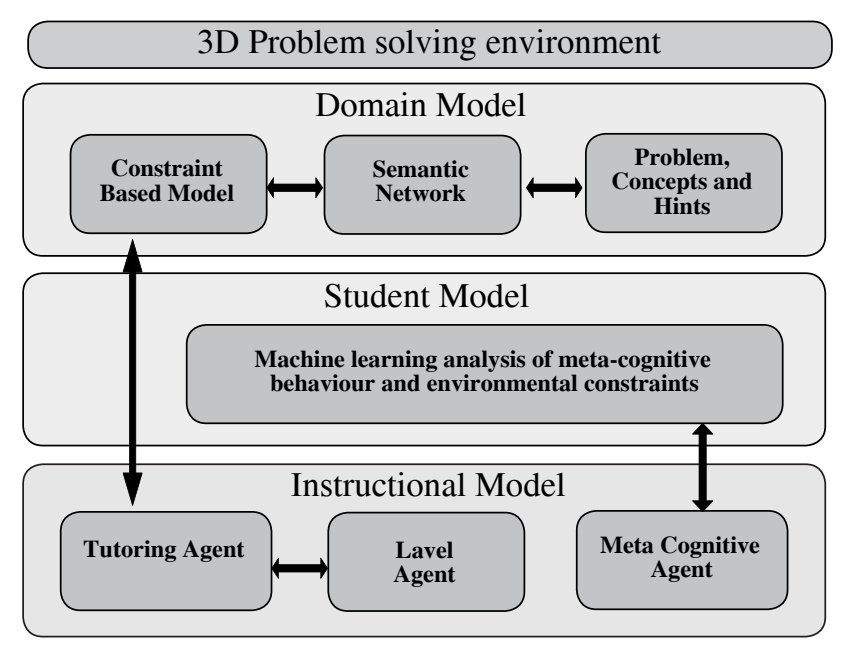

Figure 10. A conceptual model for 3D games-based learning intelligent tutoring system using multi-agent and machine learning technologies by Mills \& Darlgarno (2007).

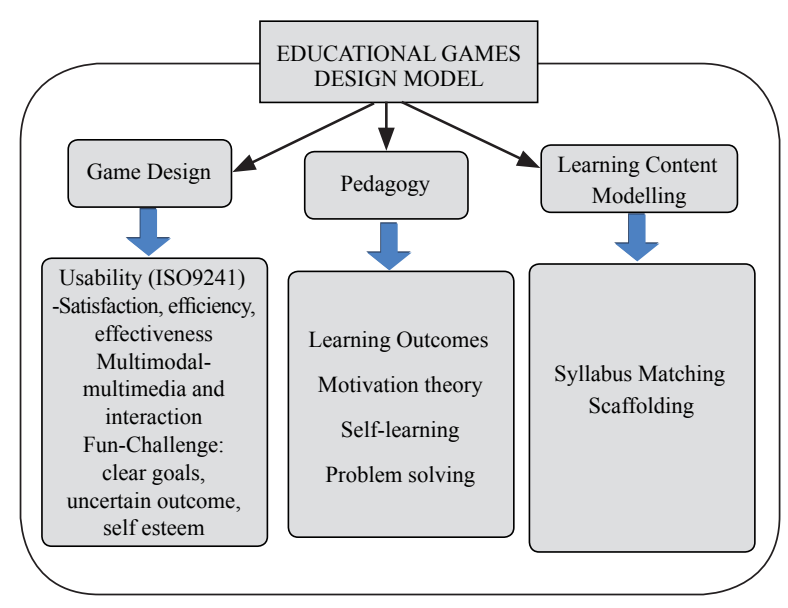

Figure 11. Educational Game Design Model

Figure 11 is a framework that combines learning elements (pedagogy and learning contents) with development elements (game design) (Ibrahim \& Jaafar, 2009). The authors have emphasized on the usability that comprises of efficiency, competence, and satisfaction in both the game design and learning content of the game as compared to the FDF. 


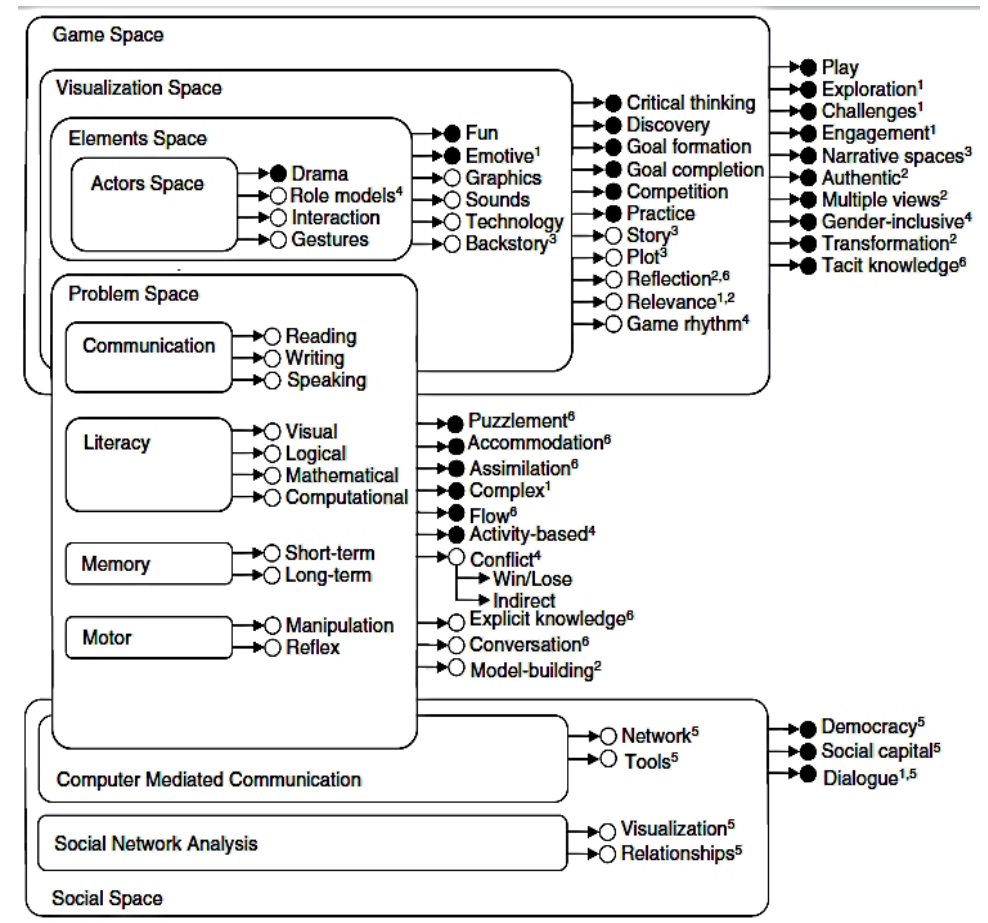

Figure 12. Game Object Model II

The Game-Object Model II (GOM II) (see Figure 12), based on objectoriented programming concepts, provides a theoretical basis for the design of educational games. GOM II is able to create tension between game elements and pedagogical dimensions (Amory, 2007). This model is an enhancement from the Game Object Model I (GOM I) developed in 2003 by Amory. GOM I does not have the collaboration between the spaces of the framework whereas GOM II provides the collaboration. Objects are interconnected into three major spaces, namely challenges, narrative, and conversation. Components of the model categorized as concrete or interface. The abstract interfaces will conclude the pedagogical fitting of a game while the concrete interfaces will show if the game is able to achieve the educational objective. Social space that includes relationship among the equipment or social factors is not having any connectivity to the visualization space, which has more or less the same factors as representation dimension of FDF. This shows that, although the models are able to support development of educational games and provide the mechanism to review the game on how well a game achieves educational objective; it is also agreed that the model can be easily misconceived to suit different viewpoints. 
Figure 13, shows an educational game development methodology that incorporates the FDF as the design and validation framework (Jarvis \& de Freitas, 2009). Although not explicitly captured in Figure 13, the methodology also incorporates controlled learning (Forehand, 2010), learning models (Garris et al., 2002; Wilson et al., 2009), flow theory (Csikszentmihalyi, 1990) and engagement theory (Moser, 2002).

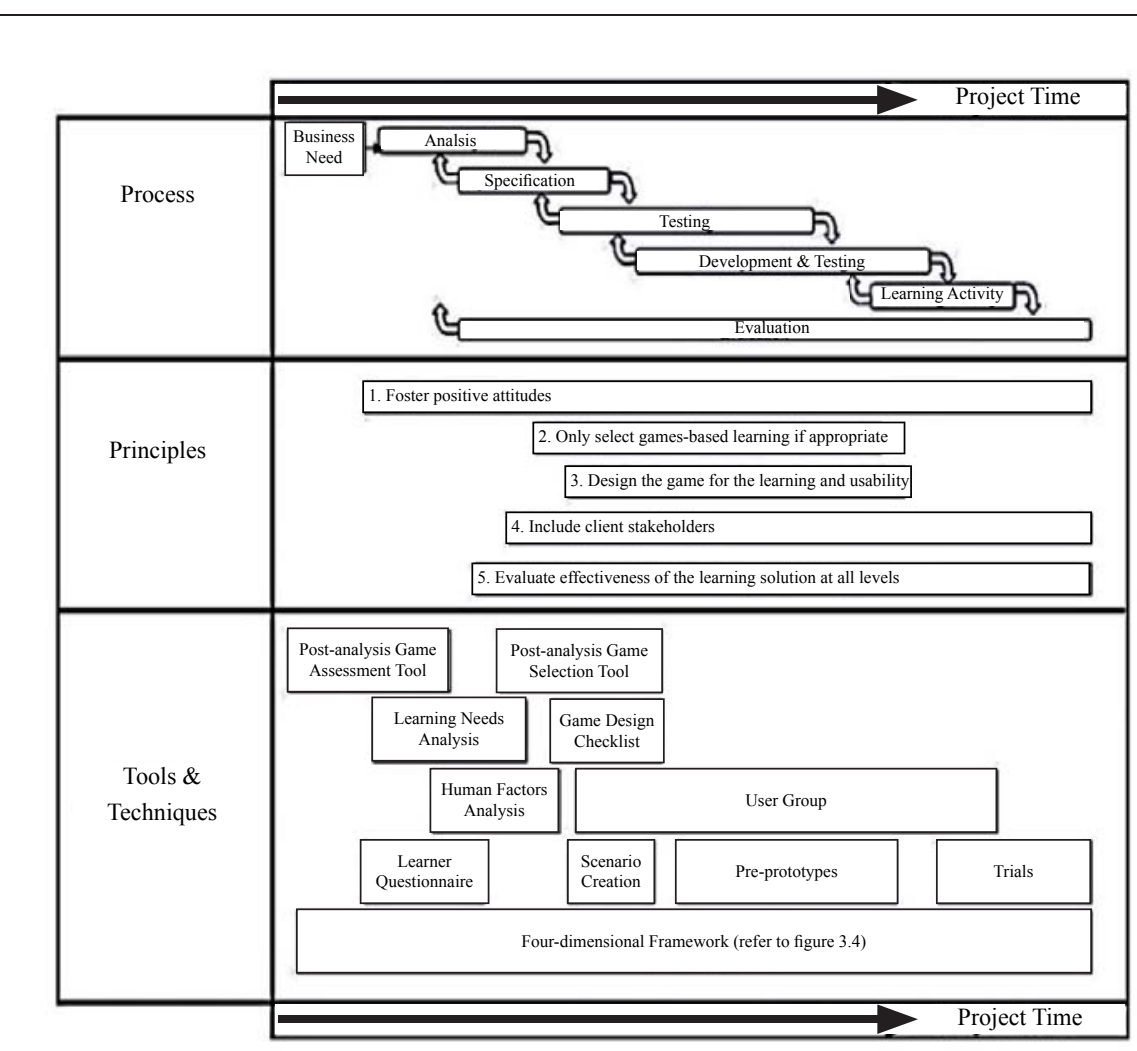

Figure 13. Serious-games design model: process, principles, and tools and techniques for supporting serious-games design and evaluation (Jarvis \& de Freitas, 2009) .

To summarize the frameworks in perspective of designing and learning educational games, there are four major movements analyzed in the discussion $^{2}$. FDF (De Freitas \& Jarvis, 2009; De Freitas \& Oliver, 2006) proposed design elements based on experiential learning. The next movement

2 Note that the movements are not sequential evolution of the research work. It highlights the important factors that make an effective game, which the researchers focus on. 
in designing educational games is frameworks that not only specify elements but also incorporates the learning process specified in the learning theories. The learning theories being incorporated are experiential learning (Wang et al., 2010), flow theory (Finneran \& Zhang, 2003) and active learning (Garris et al., 2002). The second movement is recognition that an effective educational game should incorporate the learning process and not just the learning elements. The third movement includes in the framework other aspects of education such as national curriculum, school hours, and budget and teacher competencies. This movement highlights the importance of local factors/issues/constraints that may influence effectiveness of GBL, and considers the application of GBL in a formal education setting. The fourth movement is the frameworks evolution from the learning perspective to development perspective, and highlights that educational game effectiveness requires the combination of game design and learning process. This evolution results in the framework adopting a software model like notations (Amory, 2007), becoming more like a software architecture (Mills \& Dalgarno, 2007), including software properties such as usability (Ibrahim \& Jaafar, 2009) and becoming part of a software development methodology (Jarvis \& de Freitas, 2009).

\section{RESULTS}

The frameworks and models were analyzed based on five major categories: 1) Developing game design, 2) Well-design game, 3) Effective video game, 4) Four major learning theories, and 5) Key elements of a game. These components have been discussed in the previous section in details and the analyses' results are illustrated in Table 3.

The EGM framework has all the components under the developing game design category. Furthermore, 11 frameworks (FDF, SF, CMBD, LCL, DGBL, EGDM, OBDM, GOM2, EGM, FFCM, and SGDM) uses pedagogical effectiveness component. Nine frameworks (FDF, SF, LCL, GG, OBDM, GOM 2, EGM, FFCM, and SGDM) have implemented evaluation of game component. There are five frameworks (LCL, DGBL, OBDM, GOM 2, EGM) who use the gamification component and only two frameworks (CMBD and EGM) used cost-effectiveness component. This shows that two most critical elements, pedagogical effectiveness and evaluation of game, should be highly considered when the game design is being developed.

Second category, well-designed games, there are eleven frameworks (FDF, CMBD, LCL, DGBL, EGDM, GG, OBDM, GOM 2, EGM, FFCM and SGDM) which have used interactive problem solving component and ten frameworks (FDF, SF, LCL, DGBL, EGBL, OBDM, GOM 2, EGM, FFCM, 
and SGDM) used specific goals/rules components for well-designed games. Ongoing feedback component has been used in eight frameworks (FDF, CMBD, LCL, GG, GOM 2, EGM, FFCM, and SGDM). Adaptive challenge is also an important component that is considered by six frameworks (SF, CMBD, GG, OBDM, GOM 2, and EGM). There are five frameworks (FDF, LVL, GOM 2, EGM, and FFCM) that have used sensory stimuli, where they have added fun to the game design, whereas, control of design is also involved in the five frameworks (SF, LCL, GG, EGM, and FFCM). The least involved component, uncertainty to gain engagement, is implemented in two frameworks (DGBL and GOM 2). With this analysis, we can easily understand that many researchers have considered the interactive problem solving design of the game and the games must have specific goals/rules where the learners are aware of. Ongoing feedback must also be considered while designing the game as it provides and update the learners as they play the game. Only six frameworks used the adaptive challenges, which is indeed a serious problem. If the game is adaptive, it is more interactive, and with constant challenges provided to the learners, the learners are able to achieve the goals or objectives easily.

\section{Table 3}

Summary Matrix of Game-based learning Frameworks and Models

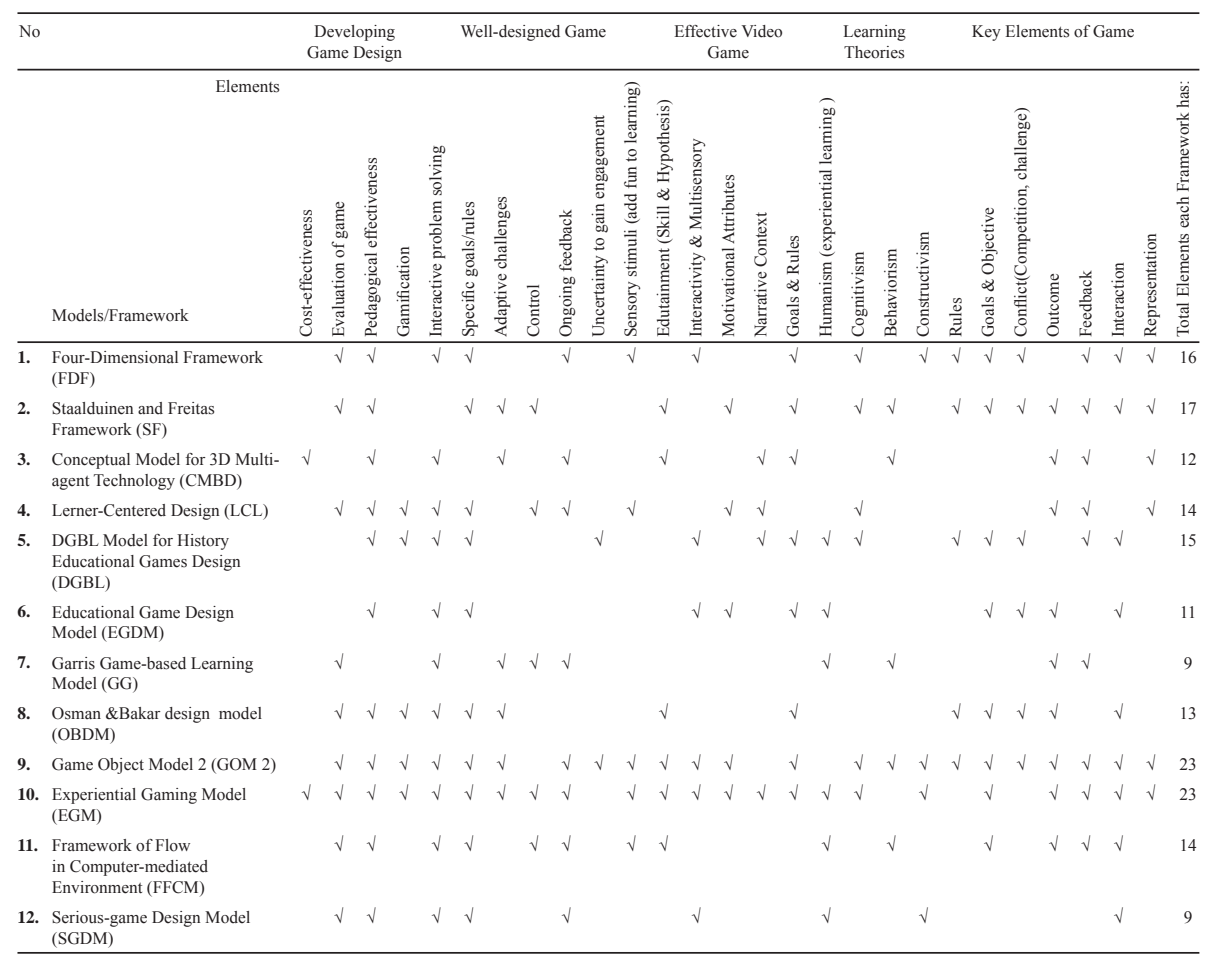


Third category, effective video game, has five elements. Only goals and rules component are used in eight frameworks (FDF, SF, CMBD, DGBL, EGDM, OBDM, GOM 2, and EGM). The edutainment component, which combines skills and hypothesis of the game, was implemented in six frameworks (SF, CMBD, OBDM, GOM 2, EGM, and FFCM). In addition, six frameworks (FDF, DGBL, EGDM, GOM 2, EGM, and SGDM) implemented interactive $\&$ multisensory component. Motivational attribute, is known to be a very crucial component, was implemented by only five frameworks (SF, LCL, EGDM, GOM 2, and EGM). The last component, narrative content, which also highlighted by many authors as a very critical component for effective video games, is only mentioned in four frameworks (CMBD, LCL, DGBL, and EGM).

The fourth category is the learning theories. There are six frameworks (DGBL, EGDM, GG, FFCM, EGM, and SGDM) that have used humanism theory while six other frameworks (FDF, SF, LCL, DGBL, GOM 2, and EGM), used cognitivism. This shows that the authors who have developed the framework mostly consider these theories. Furthermore, five frameworks (SF, CMDB, GG, OBDM, and FFCM) have used behaviorism theory. Finally yet importantly, four frameworks (FDF, GOM 2, EGM, and SGDM) have implement constructivism theory. The authors have showed humanism and cognitivism to be the most crucial theory; however, four major theories must be revised before or while developing the frameworks.

The fifth category is the key elements of game. There are seven key elements in the Table 3. All the seven elements were implemented in two frameworks (SF and GOM 2). There are nine frameworks (SF, CMBD, LCL, EGDM, GG, OBDM, GOM 2, EGM, and FFCM) that discuss outcome element importance and include this element into their framework. Feedback is also implemented in nine frameworks (FDF, SF, CMBD, LCL, DGBL, GG, GOM 2, EGM, and $\mathrm{FFCM}$ ). Interaction element is also emphasized in nine frameworks (FDF, SF, DGBL, EGDM, OBDM, GOM 2, EGM, FFCM, and SGDM). Six frameworks (FDF, SF, DGBL, EGDM, OBDM, and GOM 2) emphasized on the conflict component where they believed that competition and challenge is very important to be considered. Representation element is also implemented in six frameworks (FDF, SF, CMBD, LCL, GOM 2, and EGM). Last but not least, there are five frameworks (FDF, SF, DGBL, GOM 2 and EGM) have implemented the rules that need to be followed by the learners as they play the educational game.

Frameworks have been proposed from the developers' perspective and these frameworks covers some development concerns such as development process and usability. However, the research from developers' perspective is 
still immature, as they lack in interpreting the frameworks in perspective of methods or technique that can be adopted for the game developers to develop their games efficiently.

Research from the development perspective is important because educational games are also a type of software and as such, software engineering practices should be practice in its development. According to (Hirumi \& Stapleton, 2009), developing educational games require the involvement of people from education and game development. Therefore, communication between both parties is essential in ensuring a successful development. Furthermore, the importance of communication between stakeholders is well established in the field of software engineering. A proof of this fact is the creation of Agile development model (Sommerville, 2006) where one of the main principal of agile development is active communication between stakeholders. In educational game development, the method of communication between stakeholders, the roles played by each stakeholder and the information that is provided by each stakeholder are among the topics that are still under research. The information (also known as requirements in software engineering) given by clients (i.e. teachers, students and educationist) needs to be captured and the method to do this is not well established for educational games. Some of the common methods to record the requirements for other types of software are formal methods, modelling, and natural language documentation. The research on adopting these methods to educational game development, to the best of the authors' knowledge, is still unheard of.

As has been discussed in this paper, there exist frameworks and modeling languages for designing educational games. However, from software engineering perspective, research in the design of educational games is still in its infancy level. The translation from the requirements to the model and framework is yet to be elaborated. Furthermore, there is no discussion on how to build the educational games from the models or use the models for verifying effectiveness of the educational games. Model-Driven Engineering (MDE) (Meyers \& Vangheluwe, 2011; Molina \& Toval, 2009; Nodenot, Caron, Le Pallec, \& Laforcade, 2007; Tang \& Hanneghan, 2010; 2011) is a relatively new research field in software engineering that encourage the use of models to represent requirements and use model transformations to automatically generate models and codes. For example (Yang \& Tan, 2007) creates transformation rules to transform a functional model into an object-oriented model. The authors in (L. Rahim \& Whittle, 2010) developed and verified UML state machine to Java code generators. Another review by (Rahim, 2007) also use model transformations to translate Object Constraint Language (OCL) and UML class diagram to PVS for verification of OCL and class diagram. MDE can be the next way forward for educational game development as it 
leverages on the use of well-defined models of the game. However, for the development of educational games to use MDE, a domain-specific modeling language with well define semantics is required. From our survey, GOM2 can be used as a modeling language but it only covers the structural elements of the game. Modeling language for the behaviors of educational game is to our knowledge not available. Another field that may be of benefit to educational game development is model-based testing (MBT). MBT is a method to improve the testing process of software by referring to the models for guidance (Apfelbaum \& Doyle, 1997; Broy, 2005; Dalal et al., 1999; Hemmati, Arcuri, \& Briand, 2013; Prensky, 2005; Shafique \& Labiche, 2010; Timmer, Brinksma, \& Stoelinga, 2011).

Verifying effectiveness of the game has been explored many times (Omar \& Jaafar, 2010) and the most common method is a combination of acceptance testing and quantitative/qualitative research methods. Other methods such as unit testing, white-box testing and verification using models are yet to be well known. Further research is required for these areas:

1) Communications between stakeholders to effectively capture all requirements.

2) Modelling languages to be used in all parts of development from requirements to detailed design.

3) Verification of educational games effectiveness from models and designs.

4) Traceability from requirements to code.

5) Testing educational games other methods other than acceptance testing.

6) Using Model-Driven Engineering (MDE) (Barros, Dantas, Veronese, \& Werner, 2006; Brambilla, Cabot, \& Wimmer, 2012; Fardoun, Montero, \& López Jaquero, 2009; Gibbons, Nelson, \& Richards, 2000; Mislevy \& Haertel, 2006; Tang \& Hanneghan, 2011) in the development of educational games.

\section{CONCLUSION}

This paper provides a review on several frameworks for the development of educational games. The authors have identified four different types of movement in the educational game design framework research. The first movement is the framework demonstrates the key elements of an educational game. The second movement produced frameworks that are built around learning theories and include the process of learning. The third movement starts producing frameworks that go beyond learning theories and add elements 
important in GBL implementation in a formal education setting. The fourth movement is a change from learning centric framework to game development centric framework.

The authors have also analyzed the compliance of these design frameworks with several effective educational games criteria and their support of learning theories. The learning theories most supported by the design frameworks are experiential learning and cognitivism. On the other hand, the effective educational games criteria that researchers focused more are pedagogical effectiveness, interactive, specific objectives and goals, and feedback. The authors have also discussed and recommended a few research topics that are important to educational games development but are not emphasized enough by the research community.

For the future work, the authors will focus their research towards modeling educational games with high emphasis on verifying the effectiveness of the games from its models. Towards this end, the authors will work on improving the existing frameworks to highlight the relationships between the elements of an educational game. These relationships are crucial in establishing how one element collaborates with other elements to ensure effectiveness of the game. Without these relationships, effectiveness of the design cannot be measured.

\section{REFERENCES}

Bakar, N. A. A. A., Hashim, S., \& Shiratuddin, M. F. (2002). Virtual Reality: A review of its implementation in the Virtual Physics lab. The Journal of Information Communication Technology, 1(1), 69 - 85.

Admiraal, W., Huizenga, J., Akkerman, S., \& Dam, G. T. (2011). The concept of flow in collaborative game-based learning. Computers in Human Behavior, 27(3), 1185-1194.

Amory, A. (2007). Game object model version II: A theoretical framework for educational game development. Educational Technology Research and Development, 55(1), 51-77.

Amory,A., \& Seagram, R. (2003). Educational game models: Conceptualization and evaluation. South African Journal of Higher Education, 17(2), 206-217.

Apfelbaum, L., \& Doyle, J. (1997). Model based testing. Paper presented at the Software Quality Week Conference.

Arnab, S., Berta, R., Earp, J., De Freitas, S., Popescu, M., Romero, M., Usart, M. (2012). Framing the adoption of serious games in formal education. Electronic Journal of e-Learning, 10(2), 159-171. 
Baranowski, T., Buday, R., Thompson, D. I., \& Baranowski, J. (2008). Playing for real: Video games and stories for health-related behavior change. American journal of preventive medicine, 34(1), 74-82.

Barker, D., Quennerstedt, M., \& Annerstedt, C. (2013). Inter-student interactions and student learning in health and physical education: A post-Vygotskian analysis. Physical Education and Sport Pedagogy (ahead-of-print), 1-18.

Barros, M. D. O., Dantas, A. R., Veronese, G. O., \& Werner, C. M. (2006). Model-driven game development: Experience and model enhancements in software project management education. Software Process: Improvement and Practice, 11(4), 411-421.

Becker, K. (2009). Video Game Pedagogy Games: Purpose and Potential in Education (pp. 73-125): Springer.

Brambilla, M., Cabot, J., \& Wimmer, M. (2012). Model-driven software engineering in practice. Synthesis Lectures on Software Engineering, $1(1), 1-182$.

Bransford, J. D., Brown, A. L., \& Cocking, R. R. (1999). How people learn: Brain, mind, experience, and school: National Academy Press.

Broy, M. (2005). Model-based testing of reactive systems: Advanced lectures (3472): Springer.

Bruner, J. (1961). The act of discovery. Harvard Educational Review.

Charsky, D., \& Ressler, W. (2011). Games are made for fun: Lessons on the effects of concept maps in the classroom use of computer games. Computers \& Education, 56 (3), 604-615.

Chen, H., Wigand, R. T., \& Nilan, M. S. (1999). Optimal experience of web activities. Computers in Human Behavior, 15(5), 585-608.

Cheng, Y. M., Lou, S. J., Kuo, S. H., \& Shih, R. C. (2013). Investigating elementary school students' technology acceptance by applying digital game-based learning to environmental education. Australasian Journal of Educational TecCombs, A. W. (1981). Humanistic education: Too tender for a tough world? The Phi Delta Kappan, 62(6), 446-449.

Csikszentmihalyi, M. (1990). Flow: The psychology of optimal experience. New York,: Harper \& Row Publishers, Inc.

Csikszentmihalyi, M. (1997). Finding flow: The psychology of engagement with everyday life: Basic Books.

Dalal, S. R., Jain, A., Karunanithi, N., Leaton, J., Lott, C. M., Patton, G. C., \& Horowitz, B. M. (1999). Model-based testing in practice. Paper presented at the Proceedings of the 21st international Conference on Software Engineering.

Dalgarno, B., \& Lee, M. J. (2012). Exploring the relationship between afforded learning tasks and learning benefits in $3 D$ virtual learning environments. Paper presented at the Proceedings of ASCILITE- 
Australian Society for Computers in Learning in Tertiary Education Annual Conference.

De Freitas, S., \& Jarvis, S. (2009). Towards a development approach for serious games. Games-based learning advancements for multi-sensory humancomputer interfaces: Techniques and effective practices. IGI Global. Hershey, PA.

De Freitas, S., \& Oliver, M. (2006). How can exploratory learning with games and simulations within the curriculum be most effectively evaluated? Computers \& Education, 46(3), 249-264.

Dede, C., Clarke, J., Ketelhut, D. J., Nelson, B., \& Bowman, C. (2005). Students' motivation and learning of science in a multi-user virtual environment. Paper presented at the American Educational Research Association Conference, Montreal, Canada.

Dondlinger, M. J. (2007). Educational video game design: A review of the literature. Journal of Applied Educational Technology, 4(1), 21-31.

Egenfeldt-Nielsen, S., Smith, J. H., \& Tosca, S. P. (2008). Understanding video games: The essential introduction: Routledge.

Fardoun, H., Montero, F., \& López Jaquero, V. (2009). ELearniXML: Towards a model-based approach for the development of e-Learning systems considering quality. Advances in Engineering Software, 40(12), 1297-1305.

Finneran, C. M., \& Zhang, P. (2003). A person-artefact-task (PAT) model of flow antecedents in computer-mediated environments. International Journal of Human-Computer Studies, 59(4), 475-496.

Fisch, S. M. (2005). Making educational computer games educational. Paper presented at the Proceedings of the 2005 Conference on Interaction Design and Children.

Forehand, M. (2010). Bloom's taxonomy. Emerging perspectives on learning, teaching, and technology, 41-47.

Garris, R., Ahlers, R., \& Driskell, J. E. (2002). Games, motivation, and learning: A research and practice model. Simulation \& gaming, 33(4), 441-467.

Garzotto, F. (2007). Investigating the educational effectiveness of multiplayer online games for children. Paper presented at the Proceedings of the 6th international conference on Interaction Design and Children.

Ge, D. I. D. E. X. (2012). Assessment in Game-Based learning. Foundations, Innovations and Perspectives XXVII.

Gee, J. P. (2005). Good video games and good learning. Paper presented at the Phi Kappa Phi Forum.

Gibbons, A. S., Nelson, J., \& Richards, R. (2000). The nature and origin of instructional objects. The instructional use of learning objects. Bloomington, IN: Association for Educational Communications and Technology. 
Gredler, M. E. (1996). Educational games and simulations: A technology in search of a (research) paradigm. In Jonassen, D. H. (Ed.), Handbook of research for educational communications dan technology (521-539). New York: Macmillan.

Gress, C. L., Fior, M., Hadwin, A. F., \& Winne, P. H. (2010). Measurement and assessment in computer-supported collaborative learning. Computers in Human Behavior, 26(5), 806-814.

Hays, R. T. (2005). The effectiveness of instructional games: A literature review and discussion: DTIC Document.

Hemmati, H., Arcuri, A., \& Briand, L. (2013). Achieving scalable modelbased testing through test case diversity. ACM Transactions on Software Engineering and Methodology (TOSEM), 22(1), 6.

Herrington, J., \& Oliver, R. (2000). An instructional design framework for authentic learning environments. Educational Technology Research and Development, 48(3), 23-48.

Hirumi, A., \& Stapleton, C. (2009). Applying pedagogy during game development to enhance game-based learning Games: Purpose And Potential in Education (127-162): Springer.

Hofer, M. (2005, January). Massivelt multiplayer online games and their implications for game-based learning, 1-13.

Hoffman, D. L., \& Novak, T. P. (1996). Marketing in hypermedia computermediated environments: conceptual foundations. The Journal of Marketing, 50-68.

Holland, W., Jenkins, H., Squire, K., Miller, Z. N., O'Driscoll, A., Shresthova, S., ... Todd, K. (2003). Theory by design. Video game theory reader, 25-46.

Hussin, H., Suhaimi, M. A., \& Bawi, Z. B. A. (2004). ICT and school transformation: An empiracle study on the perception of principals in the Klang Valley area on the Malaysian Smart School. The Journal of Information and Communication Technology, 3(2).

Hwang, G. J., Sung, H. Y., Hung, C. M., \& Huang, I. (2013). A learning style perspective to investigate the necessity of developing adaptive learning systems. Educational Technology \& Society, 16(2), 188-197.

Ibrahim, R., \& Jaafar, A. (2009). Educational games (EG) design framework: Combination of game design, pedagogy and content modeling. Paper presented at the Electrical Engineering and Informatics, 2009. ICEEI'09. International Conference on.

Jarvis, S., \& de Freitas, S. (2009). Evaluation of an immersive learning programme to support triage training. Paper presented at the Games and Virtual Worlds for Serious Applications, 2009. VS-GAMES'09. Conference in.

Jong, M., Shang, J., Lee, F. 1., \& Lee, J. H. (2010). Constructivist learning through computer gaming. Technologies Shaping Instruction and Distance Education: New Studies and Utilizations, 207-222. 
Jong, M. S., Lee, F. 1., Lee, J. H.-M., \& Shang, J. (2011). A case study of an academic achievement-oriented student in game-based learning. Paper presented at the Advanced Learning Technologies (ICALT), 2011 11th IEEE International Conference on.

Ke, F. (2009). A qualitative meta-analysis of computer games as learning tools. Handbook of research on effective electronic gaming in education, 1, 1-32.

Ke, F. (2013). Computer-game-based tutoring of mathematics. Computers \& Education, 60(1), 448-457.

Ke, F. (2014). An implementation of design-based learning through creating educational computer games: A case study on mathematics learning during design and computing. Computers \& Education, 73, 26-39.

Kebritchi, M., \& Hirumi, A. (2008). Examining the pedagogical foundations of modern educational computer games. Computers \& Education, 51(4), 1729-1743.

Kiili, K. (2005). Content creation challenges and flow experience in educational games: The IT-Emperor case. The Internet and Higher Education, 8(3), 183-198.

Kiili, K. (2005). Digital game-based learning: Towards an experiential gaming model. The Internet and Higher Education, 8(1), 13-24.

Klopfer, E., Osterweil, S., \& Salen, K. (2009). Moving learning games forward: Obstacles, opportunities and openness (White Paper). Cambridge, MA: The Education Arcade, Massachuesetts Institute of Technology.

Kovačević, I., Minović, M., Milovanović, M., De Pablos, P. O., \& Starčević, D. (2013). Motivational aspects of different learning contexts:"My mom won't let me play this game...". Computers in Human Behavior, 29(2), 354-363.

Krotoski, A., Entertainment, \& Association, L. S. P. (2004). Chicks and joysticks: An exploration of women and gaming (White Paper): Elspa.

Kruger, J. (2012). A design-based research approach implementing a palette of educational technologies to foster 21st century skills. Paper presented at the ASCILITE-Australian Society for Computers in Learning in Tertiary Education Annual Conference.

Lalji, Z., \& Good, J. (2008). Designing new technologies for illiterate populations: A study in mobile phone interface design. Interacting with Computers, 20(6), 574-586.

Latif, R. A. (2007). Understanding Malaysian students as gamers: Experience. Paper presented at the Proceedings of the 2nd International conference on Digital Interactive Media In Entertainment and Arts.

Lee, K., \& Kim, M. (2004). The rise of China and the Korean firms looking for a new division of labor. Paper presented at the conference on Korea and The World Economy, Sungkyunkwan University, Seoul, July. 
Lester, J. C., Spires, H. A., Nietfeld, J. L., Minogue, J., Mott, B. W., \& Lobene, E. V. (2014). Designing game-based learning environments for elementary science education: A narrative-centered learning perspective. Information Sciences, 264, 4-18.

Li, K. C., Huang, J. C., Heh, J. S., Chen, C. T., Wang, H. C., \& Yeh, S. W. (2010). Designing game-based learning framework-a motivation-driven approach. Paper presented at the Advanced Learning Technologies (ICALT), 2010 IEEE 10th International Conference on.

McClarty, K. L., Orr, A., Frey, P. M., Dolan, R. P., Vassileva, V., \& McVay, A. (2012). A literature review of gaming in education. Gaming in Education.

Mellecker, R. R., Witherspoon, L., \& Watterson, T. (2013). Active learning: Educational experiences enhanced through technology-driven active game play. The Journal of Educational Research, 106(5), 352-359.

Merriam, S. A. C., RS. (1999). Learning in adulthood: A comprehensive guide. San Francisco, CA: Jossey-Bass.

Meyers, B., \& Vangheluwe, H. (2011). A framework for evolution of modelling languages. Science of Computer Programming, 76(12), 1223-1246.

Mikropoulos, T. A., \& Natsis, A. (2011). Educational virtual environments: A ten-year review of empirical research (1999-2009). Computers \& Education, 56(3), 769-780.

Mills, C., \& Dalgarno, B. (2007). A conceptual model for game-based intelligent tutoring systems. Proceedings of the 2007 Australasian Society for Computers in Learning in Tertiary Education.

Mislevy, R. J., \& Haertel, G. D. (2006). Implications of evidence centered design for educational testing. Educational Measurement: Issues and Practice, 25(4), 6-20.

Molina, F., \& Toval, A. (2009). Integrating usability requirements that can be evaluated in design time into Model Driven Engineering of Web Information Systems. Advances in Engineering Software, 40(12), 1306-1317.

Moreno-Ger, P., Burgos, D., Martínez-Ortiz, I., Sierra, J. L., \& FernándezManjón, B. (2008). Educational game design for online education. Computers in Human Behavior, 24(6), 2530-2540.

Moser, R. (2002). A methodology for the design of educational computer adventure games.

Nodenot, T., Caron, P. A., Le Pallec, X., \& Laforcade, P. (2007). Applying Model Driven Engineering Techniques and tools to the planets game learning scenario. Journal of Interactive Media in Education, 2008(2).

Omar, H., Ibrahim, R., \& Jaafar, A. (2011). Methodology to evaluate interface of educational computer game. Paper presented at the Pattern Analysis and Intelligent Robotics (ICPAIR), 2011 International Conference on. 
Omar, H. M., \& Jaafar, A. (2010). Challenges in the evaluation of educational computer games. Paper presented at the Information Technology (ITSim), 2010 International Symposium.

Osman, K., \& Bakar, N. A. (2012). Educational computer games for Malaysian classrooms: Issues and challenges. Asian Social Science, 8(11), p75.

Pivec, M., \& Dziabenko, O. (2004a). Game-based learning framework for collaborative learning and student e-teamwork. Retrieved from: http:// www. unigame. net/html/publications.

Pivec, M., \& Dziabenko, O. (2004b). Game-based learning in universities and lifelong learning:" UniGame: Social skills and knowledge training" game concept. Journal of Universal Computer Science, 10(1), 14-26.

Poulsen, M. (2011). Learning by producing The Gameit Handbook (87).

Prensky, M. (2003). Digital game-based learning. Computers in Entertainment (CIE), 1(1), 21-21.

Prensky, M. (2005). Computer games and learning: Digital game-based learning. Handbook of Computer Game Studies, 18, 97-122.

Quinn, C. N. (2005). Engaging learning: Designing e-learning simulation games. John Wiley \& Sons:

Rahim, L., \& Whittle, J. (2010). Verifying semantic conformance of state machine-to-Java code generators model driven engineering languages and systems (pp. 166-180): Springer.

Rahim, L. A. (2007). Transforming OCL to PVS: Using theorem proving support for analysing model constraints.

Randel, J. M., Morris, B. A., Wetzel, C. D., \& Whitehill, B. V. (1992). The effectiveness of games for educational purposes: A review of recent research. Simulation \& Gaming, 23(3), 261-276.

Romli, R., Shiratuddin, M. F., \& Hashim, S. (2003). The virtual chemistry lab (VC-L): Virtual Reality as a learning tool for Malaysia's secondary school. The Journal of Information and Communication Technology, 2(1), 81-92.

Shafique, M., \& Labiche, Y. (2010). A systematic review of model based testing tool support. Software Quality Engineering Laboratory, Department of Systems and Computer Engineering, Carleton University, Technical Report SCE-10-04.

Shute, V., \& Ke, F. (2012). Games, learning, and assessment. Assessment in Game-Based Learning (pp. 43-58): Springer.

Smith, J. (1999). Learning theory. The Encyclopedia of Informal Education.

Smythe, M. (2012). Toward a framework for evaluating blended learning. Paper presented at the ASCILITE-Australian Society for Computers in Learning in Tertiary Education Annual Conference.

Sommerville, I. (2006). Software engineering (8th ed.): Eddison Wesley. 
Squire, K., \& Jenkins, H. (2003). Harnessing the power of games in education. Insight, 3(1), 5-33.

Staalduinen V., J. P., \& de Freitas, S. (2010). A game-based learning framework: Linking game design and learning outcomes. In learning to Play: Exploring the Future of Education with Video Games. Khine, MyintSwe (Ed.). New York: Peter Lang Publishers.

Takaoka, R., Shimokawa, M., \& Okamoto, T. (2011). A framework of educational control in game-based learning environment. Paper presented at the Advanced Learning Technologies (ICALT), 2011 11th IEEE International Conference.

Tan, P. H., Ling, S. W., \& Ting, C. Y. (2007). Adaptive digital game-based learning framework. Paper presented at the Proceedings of the 2nd international conference on Digital Interactive Media in Entertainment and Arts.

Tang, S., \& Hanneghan, M. (2010). A model-driven framework to support development of serious games for game-based learning. Paper presented at the Developments in E-systems Engineering (DESE), 2010.

Tang, S., \& Hanneghan, M. (2011). State-of-the-art model driven game development: A survey of technological solutions for game-based learning. Journal of Interactive Learning Research, 22(4), 551-605.

Tham,L., \& Tham, R. (2012). Is Game-Based Learning an effective instructional strategy to engage students in higher education in Singapore? A Pilot Study. Editor Managing Editor, 8(1).

Thorndike, E. (1913). Educational psychology, 1.

Timmer, M., Brinksma, H., \& Stoelinga, M. (2011). Model-based testing.

Tiong, K., \& Yong, S. (2008). Learning through computer game design: Possible success (or failure) factors. Paper presented at the The 16th International Conference on Computers in Education.

Van Eck, R. (2006). Digital game-based learning: It's not just the digital natives who are restless. EDUCAUSE Review, 41(2), 16.

Vogel, J. J., Vogel, D. S., Cannon B., J., Bowers, C. A., Muse, K., \& Wright, M. (2006). Computer gaming and interactive simulations for learning: A meta-analysis. Journal of Educational Computing Research, 34(3), 229-243.

Wang, C. S., Liu, C. C., \& Li, Y. C. (2011). A game-based learning content design framework for the elementary school children education. Paper presented at the Nano, Information Technology and Reliability (NASNIT), 2011 15th North-East Asia Symposium.

Wang, T. L., Chen, T. K., \& Tseng, Y. F. (2010). An leaner-centred, gamebased, learning framework for typing games in English course. Paper presented at the Computer Communication Control and Automation (3CA), 2010 International Symposium. 
Whitton, N. (2012). The place of game-based learning in an age of austerity. Electronic Journal of e-Learning, 10(2), 249-256.

Whitton, N. J. (2007). An investigation into the potential of collaborative computer game-based learning in higher education. Edinburgh Napier University.

Wilson, K., Bedwell, W., Lazzara, E., Salas, E., Burke, S., Estock, J., . . . Conkey, C. (2009). Relationships between game attributes and learning outcomes review and research proposals. Simulation \& Gaming, 40(2), 217-266.

Wolfe, J. (1997). The effectiveness of business games in strategic management course work. Simulation \& Gaming, 28(4), 360-376.

Wouters, P., \& Van Oostendorp, H. (2013). A meta-analytic review of the role of instructional support in game-based learning. Computers \& Education, 60(1), 412-425.

Wu, W. H., Hsiao, H. C., Wu, P. L., Lin, C. H., \& Huang, S. H. (2012). Investigating the learning-theory foundations of game-based learning: a meta-analysis. Journal of Computer Assisted Learning, 28(3), 265-279.

Yang, Y., \& Tan, H. B. K. (2007). Design and implementation of a system for transforming functional model into OO Model. The Journal of Information Communication Technology, 6, 1 - 17.

Yue, S., Zin, N., \& Jaafar, A. (2009). Digital Game-based learning (DGBL) model and development methodology for teaching history. 8(2), 322333. 